\title{
La cuestión de la organización del gobierno y la administración insulares en la Comunidad Autónoma de las Islas Baleares
}

\author{
Luciano Parejo Alfonso \\ Catedrático de Derecho Administrativo \\ Universidad Carlos III de Madrid
}

SUMARIO: I. INTRODUCCIÓN. II. EL MARCO DE REFERENCIA PARA EL LEGISLADOR AUTÓNOMICO. 1. La composición y articulación internas del marco definido por el pertinente bloque de la constitucionalidad. 2. La Isla en el orden constitucional de la organización territorial del Estado. 3. La Isla en el EAIB. 3.1. Las disposiciones estatutarias generales. 3.2. Las disposiciones relativas a las competencias autonómicas. 3.3. La regulación estatutaria de las instituciones de la Comunidad Autónoma. 3.4. La determinación estatutaria de los Consejos Insulares como instituciones locales específicas o de trascendencia autónomica. 4. La Isla en la legislación básica de régimen local. III. LA CONFIGURACIÓN CONSTITUCIONAL DEL GOBIERNO Y LA ADMINISTRACIÓN LOCAL COMO AUTODETERMINACIÓN DEMOCRÁTICA Y A VIGENTE ORGANIZACIÓN DE LA INSTANCIA INSULAR POR LA LbCI01.

\section{INTRODUCCIÓN}

La renovación del régimen legal específico de los Consejos Insulares que, para su actualización conforme a la evolución del modelo de organización territorial interna de la Comunidad Autónoma de las Islas Baleares, se ha plasmado en la vigente Ley 8/2000, de 27 de octubre, del Parlamento de dicha Comunidad (en adelante LbCI00), volvió a desencadenar un interesante debate sobre el referido modelo centrado en la posición y función de los Consejos Insulares en la arquitectura institucional autonómica. El grado de libertad de configuración del legislador balear en función de los condicionantes impuestos por la pertenencia de los Consejos Insulares a la Administración local o, dicho de otro modo, el grado de interiorización de dichos Consejos en la referida arquitectura institucional, constituyó el eje definitorio de las dos posiciones extremas que en él se decantaron. Posiciones éstas, que no cuestionaban, sin embargo, la dirección y los objetivos mismos de la actualización del marco legal de la instancia insular: la plasmación en la organización y el funcionamiento de ésta, en tanto que Administración, de un mayor equilibrio entre los principios de legitimación democrática y autoadministración, de un lado, y los de objetividad y eficacia en la gestión de los intereses de la correspondiente colectividad insular para la mejora del servicio al interés general con sometimiento pleno a la ley y al Derecho, de otro lado. 
Puede decirse, así, que la LbCI00 se inscribe en la línea de reforma del régimen local que ha acabado afirmándose en el contexto del llamado pacto local incluso y precisamente para el arquetipo mismo del gobierno y administración locales, la instancia municipal: potenciación de la organización ejecutiva y, en el seno de la misma, del momento o dimensión burocrático-profesional (sin perjuicio de la imputación de la entera actividad ejecutiva a órganos representativos) y reconducción de la deliberante al control y fiscalización de aquélla, sin perjuicio de la retención por la misma de las decisiones más esenciales o importantes. Esta línea reformadora, que encuentra amparo en la procedencia del tratamiento diferenciado reclamado por la heterogeneidad misma de la Administración local, especialmente en su escalón basal municipal, comienza a dibujarse con la Ley catalana 22/1998, de 30 de diciembre, sobre la Carta Municipal de Barcelona, que - además de definir la línea antes apuntada de reequilibrio entre las funciones-órganos unitarios superiores del gobierno municipalapunta la desconcentración y descentralización ejecutivas internas incluso en órganos y cargos directivos ${ }^{1}$; encuentra una primera plasmación general en la Ley 11/1999, de 21 de abril, de modificación de la Ley 7/1985, de 2 de abril, reguladora de las bases del régimen local (en adelante, LrBRL), que, aparte de generalizar la apuntada línea de reforma, encuadra el régimen especial adelantado por la Carta Municipal de Barcelona al autorizar la actualización autonómica de los regímenes especiales de Barcelona y Madrid (disposición adicional sexta); y parece que va a culminar justamente con el establecimiento, actualmente en fase de preparación del que podría llegar a ser pertinente proyecto de Ley, de un régimen específico de organización y funcionamiento para los $<<$ grandes $>>$ Municipios, caracterizado cabalmente por el reforzamiento de la organización ejecutiva y su extensión más allá de la representativa ${ }^{2}$.

\footnotetext{
${ }^{1}$ Sobre el significado y alcance de la Ley catalana citada en el contexto del pacto local, en particular en punto de la <<diferenciación>> del régimen local, véase T. FonT i Llovet, La Carta Municipal de Barcelona en la Reforma del Régimen Local, Punt de Vista 7, Fundaciò Carles Pi i Sunyer d'Estudis Autonòmics i Locals, Barcelona 2000.

${ }^{2}$ De la información que ha trascendido sobre los trabajos de preparación del aludido régimen de $<<$ grandes $>>$ Municipios parece que cabe deducir las siguientes líneas fundamentales de éste:

- Mayor separación del Pleno y el Alcalde, en el sentido de que el Pleno, que se prevé que funcione disponiendo de Comisiones especializadas (una de ellas referida al seguimiento de la gestión del Alcalde) e incluso delegadas (con competencias de este carácter), puede dotarse (conforme, de otro lado, a las previsiones generales de la Ley de Régimen Jurídico de las Administraciones Públicas y del Procedimiento Administrativo común sobre los órganos colegiados) de un Reglamento propio, dotado de la condición de Reglamento Orgánico. Es claro, pues, el acercamiento del status del Pleno municipal al propio de las Asambleas parlamentarias.

- Definición funcional del Pleno, en coherencia con lo anterior y en lo sustancial, por relación al control y fiscalización de los calificados expresamente como órganos de gobierno y, por
} 
Con independencia del juego de posibles factores de estricta política insular interna a corto plazo, que aquí no interesan, lo que explica la controversia sobre los Consejos Insulares a pesar de la plena sintonía de su nueva regulación con el expuesto movimiento de reforma son los términos en modo alguno unívocos y concluyentes de las referencias del Estatuto de Autonomía a dichos Consejos, a cuya distinta interpretación — por cierto dando lugar a un curioso desdoblamiento de la posición contraria a la renovación del régimen de la instancia insular: una en el ámbito balear y

tanto, la deliberación sobre la censura al Alcalde y la cuestión de confianza planteada por éste; la aprobación de las normas locales y de los principales instrumentos equiparados a ésta (planes de urbanismo); la decisión sobre el término municipal y las competencias municipales (transferencias, descentralización, aceptación de delegaciones y encomiendas de gestión, participación en organizaciones supramunicipales), así como de ejercicio de la iniciativa económica; y la aprobación de los recursos tributarios y de los instrumentos fundamentales de gestión económico-financiera (presupuestos, cuenta general) y de personal (plantillas).

- Articulación de un verdadero complejo orgánico-funcional ejecutivo calificable, por analogía con las instancias general y autonómica, como $<<$ Gobierno $>>$ y que se quiere resaltar expresamente en la Ley cambiando la denominación de la Comisión de Gobierno por Junta de Gobierno Local, sobre la base de los principios presidencial (primacía del Alcalde como director efectivo del gobierno local), colegialidad (asignación en bloque a la Junta de Gobierno Local de las funciones ejecutivas y administrativas y determinación de la misma como órgano de colaboración con el Alcalde en la función de dirección política, todo ello con arreglo al principio de responsabilidad solidaria ante el Pleno, sin perjuicio de la responsabilidad directa de cada uno de los miembros por razón de su gestión específica) y departamentalidad (previsión de Áreas o Concejalías para la gestión de servicios comunes o desarrollo de funciones análogas bajo la responsabilidad de miembros de la Junta de Gobierno Local). Con asignación a este complejo, en bloque, de la dirección de la política municipal y la función ejecutivo-administrativa. Y la concepción desconcentrada del gobierno y la administración municipales gracias a la institucionalización de los Distritos.

$\mathrm{Al}$ alcalde se le atribuyen, en lo fundamental: la dirección de la política, el gobierno y la administración municipal (con la colaboración y, en su caso, en cooperación con la Junta de Gobierno Local); la definición de las directrices de la acción de gobierno municipal, asegurando su continuidad y pudiendo dictar bandos, decretos e instrucciones; la presidencia de la Comisión de Gobierno, el nombramiento de los Tenientes de Alcalde y los Presidentes de los Distritos; y la organización y la estructura de la Administración municipal (en todo lo no atribuido al Pleno).

- A la Junta de Gobierno Local se asigna la aprobación de los proyectos de normas a someter al Pleno, los de presupuestos anuales y los de los instrumentos de ordenación urbanística; el otorgamiento de licencias (salvo disposición sectorial distinta); el desarrollo de la gestión económica y la patrimonial; la contratación y la concertación de operaciones de crédito; la aprobación de la oferta de empleo público y las decisiones básicas en punto a la selección del personal; el nombramiento y el cese de los altos cargos directivos; y el ejercicio de la potestad sancionadora. El número de miembros de la Junta no puede exceder del tercio del número legal de Concejales, siendo todos de designación y cese libres del Alcalde entre los Concejales. Los Tenientes de Alcalde pueden ser destinatarios de delegaciones de competencias efectuadas por dicha Junta. 
la contraria en el general ${ }^{3}$ - hace expresa referencia la exposición de motivos de la $\mathrm{LbCIOO}^{4}$.

La opción final del legislador balear, con todo, huye de los extremos y hace una interpretación estatutaria ponderada, a juzgar por la exposición de motivos del vigente texto legal, en la que se sostiene que el Estatuto permite establecer premisas suficientemente seguras sobre la esencia de los Consejos, a los cuales reconoce, por imperativo constitucional, la condición de Corporaciones locales y, simultáneamente, los perfila como instituciones propias de la Comunidad Autónoma.

Se comprende, pues, que el análisis de la LbCI00 demande la clarificación previa del marco específico definido por el bloque de la constitucionalidad aquí pertinente y de la holgura que al legislador autonómico proporcione a la hora de la determinación de la organización y el funcionamiento de los Consejos Insulares ${ }^{5}$.

\section{EL MARCO DE REFERENCIA PARA EL LEGISLADOR AUTONÓMICO}

\section{La composición y articulación internas del marco definido por el pertinente bloque de la constitucionalidad}

La Constitución, en cuanto norma suprema del entero ordenamiento de ella derivado - del general-estatal, los autonómicos y locales, por hacer

\footnotetext{
${ }^{3}$ Mientras el Partido Popular sostenía y sostiene, en cuanto partido que sustenta el Gobierno de la Nación, la procedencia de la reforma del régimen local general en el contexto del pacto local precisamente en la misma dirección que la LbCI00, ese mismo partido mantuvo y mantiene posición no solo distinta, sino opuesta a la anterior en cuanto partido de la oposición en la Comunidad Autónoma de las Islas Baleares - al punto de haber planteado, y seguir manteniendo hoy, recurso de inconstitucionalidad contra ésta basado en la desnaturalización de los Consejos Insulares en cuanto Administraciones locales- . Únicamente la regulación del Estatuto de Autonomía y su interpretación pueden, en efecto, proporcionar a tal proceder siquiera sea una base formal desde la que pretender ofrecer una imagen de mínima coherencia.

${ }^{4}$ El primer párrafo del apartado II de la citada exposición de motivos, tras afirmar que el Estatuto contiene las formulaciones jurídicas determinantes de la integración de los Consejos Insulares como elementos básicos del esquema institucional de la Comunidad Autónoma, señala que $<<$ Ciertamente, la lectura de los preceptos estatutarios ha dado lugar en los últimos años a interpretaciones diversas, y en ocasiones contrapuestas, sobre la naturaleza y las características fundamentales de los entes insulares $>$.

${ }^{5}$ Esa es la metodología seguida por el propio autor en el trabajo «La regulación de los Consejos Insulares a la luz del marco constitucional y estatutario», en la obra colectiva Cuatro estudios sobre la Ley de Consejos Insulares, Institut d'Éstudis Autonòmics (Consellería de Presidència, Govern de les Illes Balears), L'esperit de les Lleis, Palma de Mallorca 2003, p. 52.
} 
referencia ahora tan sólo a los territoriales-, determina los Consejos Insulares como Administraciones locales con eficacia plena para todos dichos ordenamientos $^{6}$. Sin perjuicio ahora de cuáles sean las consecuencias que de esta calificación deban seguirse, desde el punto de vista de la interpretación sistemática del texto constitucional en cuanto unidad, es claro que impone la identificación de los títulos competenciales resultantes de lo dispuesto en la regla 18. ${ }^{a}$ (régimen jurídico de las Administraciones públicas) del número 1 del artículo $149 \mathrm{CE}$, en relación con la regla 2. ${ }^{\mathrm{a}}$ del número 1 del artículo $148 \mathrm{CE}$ como los pertinentes para el correspondiente desarrollo legislativo de la norma fundamental ${ }^{7}$. Así lo confirma desde luego el Estatuto de Autonomía de las Islas Baleares, aprobado por Ley Orgánica 2/1983, de 25 de febrero, y modificado por la Ley Orgánica 3/1999, de 8 de enero (en adelante EAIB), por el juego combinado de sus artículos 5 (que, conceptuando la organización de los Consejos Insulares como administrativa, remite a su regulación por Ley autonómica en el marco de la legislación básica del Estado, que no puede ser otra que la prevista en el artículo 149.1.18. ${ }^{a} \mathrm{CE}$ ) y 11.2. ${ }^{\text {a }}$ (que incluye la materia $<<$ régimen local $>>$ entre las de competencia legislativa autonómica de desarrollo en el marco de la legislación básica del Estado).

Queda claro así que, perteneciendo la organización y el funcionamiento de los Consejos Insulares - como objeto de legislación - a la materia $<<$ régimen local $>>$ diferenciable dentro de la mas amplia relativa al régimen de las Administraciones públicas y estableciéndose en ella el reparto competencial legislativo en términos bases-desarrollo, el bloque de la constitucionalidad al que debe acomodarse el legislador autonómico es el integrado por el conjunto CE-EAIB y la legislación básica relativa al régimen de las Administraciones públicas en general y de la local en particu$\operatorname{lar}^{8}$.

La sencillez del bloque de la constitucionalidad así integrado es solo aparente por la mayor complejidad que en el introduce la autoorganización

\footnotetext{
${ }^{6}$ Sobre este extremo se ha de volver al estudiar la regulación constitucional de la organización territorial del Estado.

${ }^{7}$ En este sentido es concluyente la doctrina del Tribunal Constitucional sentada, entre otras, en las SsTC 32/1981, de 28 de julio; 76/1983, de 5 de agosto; 14/1986, de 31 de enero, 27/1987, de 27 de febrero y $227 / 1988$, de 29 de noviembre, sobre el marco específico definido por el bloque de la constitucionalidad.

${ }^{8}$ El carácter de norma de referencia para la valoración de la constitucionalidad de las Leyes autonómicas de, en concreto, la LRBRL, es decir, la pertenencia de ésta al bloque de la constitucionalidad pertinente, está perfectamente establecido por la doctrina del Tribunal Constitucional: SsTC, entre otras, 214/1989, de 21 de diciembre y 331/1993, de 12 de noviembre.
} 
de la Comunidad Autónoma, siquiera en el plano superior —el EAIB—, en el que la correspondiente potestad alcanza su máxima expresión. Pues como con ocasión del análisis de normas legales catalanas sobre función pública ha puesto de relieve con especial claridad el Tribunal Constitucional en su reciente Sentencia 37/2002, de 14 de febrero, el título competencial autonómico previsto en el artículo 148.1.1. ${ }^{\mathrm{a}} \mathrm{CE}^{9}$, al entroncar con la normación estatutaria, es capaz de proyectarse, en efecto cruzado, cuando menos sobre la regulación de la (s) materia (s) del artículo 149.1.18. ${ }^{\mathrm{a}}$, en tanto que en éstas se manifiesta igualmente la autorreflexión sobre la propia estructura administrativa, tanto más cuando ésta — prolongando la referida a las instituciones propiamente autonómicas - ha de tomar pie - como desde luego sucede en el EAIB - en la definición de la organización territorial propia de la Comunidad Autónoma y ser congruente con ella. Es en este punto en el que juega la supuesta ambigüedad de la regulación estatutaria en punto a la posición y función de la instancia insular en la arquitectura autonómica como soporte de planteamientos distintos en la configuración de los Consejos Insulares.

Así pues, el bloque de la constitucionalidad aquí pertinente:

- No está articulado, como en principio pudiera parecer, en tres escalones con contenido perfectamente acotado, de suerte que el estatutario autonómico y el legislativo ordinario (general-estatal básico y autonómico de desarrollo) estuvieran limitados a la concreción sucesiva, sobre la base del esquema competencial dibujado por la norma constitucional, de la organización territorial predeterminada exclusivamente por ésta.

- En su integración real, la autoorganización constitucionalmente atribuida a la Comunidad Autónoma modula el cuadro anterior ya desde el escalón estatutario, capaz, respetándola, de matizar la predeterminación constitucional de la organización territorial, en función de las características propias de la correspondiente Comunidad Autónoma y para y al interior de ésta; matización ésta, que obviamente repercute - a través de la prolongación del ejercicio de la potestad de autoorganización - en el ulterior escalón legislativo ordinario, imprimiendo el sello de la proyección de dicha potestad sobre el desarrollo normativo de la regulación básica general correspondiente ${ }^{10}$.

\footnotetext{
${ }^{9}$ Asumido en el caso de la Comunidad Autónoma de las Islas Baleares en los términos del artículo 10.1. ${ }^{\mathrm{a}}$ EAIB.

${ }^{10}$ Sin que de tal proyección pueda derivarse en modo alguno quiebra de la relación lógica y jurídica entre legislación básica y legislación de desarrollo.
} 
Se comprende, pues, la importancia que para la correcta valoración de una norma legal autonómica como la LbCI00 tiene la precisión i) del orden constitucional de la organización territorial del Estado y, por tanto, del margen de decisión autoorganizativa que a las Comunidades Autónomas proporciona en punto a la Administración local insular; y ii) de los términos en que tal eventual margen de autoorganización ha sido efectiva y adecuadamente agotado en el EAIB para proporcionar específica cobertura a la legítima incorporación, en el desarrollo del régimen básico de las Administraciones públicas en general y de la local en particular, de la perspectiva propia de aquella autoorganización.

\section{La Isla en el orden constitucional de la organización territorial del Estado}

La Constitución inscribe los Consejos Insulares, en términos que no permiten duda alguna, en la Administración local que directa, aunque solo principialmente, regula. Es cierto que el artículo $137 \mathrm{CE}$, al enumerar agotadoramente los elementos componentes de la organización territorial del Estado, incluye en ésta sólo los Municipios, las Provincias y las Comunidades Autónomas. Pero no lo es menos, que i) en la alusión en dicho precepto a la Provincia debe entenderse implícita la Isla, a juzgar por el contenido del siguiente artículo $138^{11}$ y el dato de incluirse aquélla en la regulación que de la Provincia hace el ulterior artículo 141; y, en todo caso, ii) el agotamiento de los capítulos I y III del título VIII en la regulación, respectivamente, de los principios generales de la organización territorial del Estado y las Comunidades Autónomas, obliga a concluir que todas las instancias territoriales distintas de la Comunidad Autónoma deben tener su asiento regulatorio en el capítulo II de dicho título dedicado justamente a la Administración local, como efectivamente confirma, en su número 4 , el citado artículo $141 \mathrm{CE}$.

La Isla es, pues y constitucionalmente hablando, una Administración local territorial, no basal (condición de la que solo se benefician los Municipios conforme al artículo $140 \mathrm{CE}$ ), pero tampoco necesariamente - como la Provincia (art. 141.1 CE) y, en su caso, las restantes entidades supramunicipales (Comarcas; art. 141.3 CE) — una organización de

\footnotetext{
${ }^{11}$ Este precepto, también comprendido entre los principios generales de la organización territorial del Estado (capítulo I del título VIII), obliga al Estado a atender, en particular, a las circunstancias del hecho insular, en el cumplimiento de su función de garantía de la efectividad de la solidaridad consagrada nada menos que en el artículo 2 de la $\mathrm{CE}$, a cumplir velando por el equilibrio entre $<<$ las diversas partes del territorio español $>$.
} 
segundo grado, una agrupación de Municipios. El artículo 141.4 CE es inequívoco. La Isla:

a) Es una entidad local territorial necesaria en todo el territorio nacional archipielágico ${ }^{12}$. Su existencia es, pues, una decisión directa constitucional, indisponible tanto para los Estatutos de Autonomía, como para la legislación ordinaria de cualquier clase. Se trata de una decisión constitucional equiparable a la referida a Municipios y Provincias, por lo que forma parte del modelo de organización territorial del Estado definido por la norma fundamental. En este sentido, la Isla es una entidad garantizada por ésta.

b) Es una entidad que ha de tener su administración propia en forma precisamente de Cabildos o Consejos. La prescripción de una administración propia implica, en el contexto del artículo $141 \mathrm{CE}$ y desde la relevancia otorgada al <<hecho insular $>>$ (art. 138.1 CE), el reconocimiento de una colectividad insular, un círculo territorial de intereses demandante de organización para su gestión $<<$ propia $>$, su institucionalización como poder público administrativo específico. La precisión de la forma organizativa - Cabildos o Consejos - supone ciertamente, al igual que en el caso de los Municipios y las Provincias, un $<<$ reconocimiento constitutivo $>>$ de la solución organizativa preexistente ${ }^{13}$. Este reconocimiento constitutivo en modo alguno cabe entenderlo como comprensivo sin más del carácter representativo de la referida solución. La distinta historia de los Cabildos y los Consejos Insulares ${ }^{14}$ lo impide. En todo

\footnotetext{
$12<<$ En los archipiélagos, las islas tendrán además su administración propia en forma de Cabildos o Consejos $>>$ dice literalmente el precepto constitucional.

${ }^{13}$ Sobre el significado y alcance del reconocimiento constitutivo por la Constitución de las instituciones locales, véase, tempranamente, L. PARejo Alfonso, Garantía institucional y autonomía local, IEAL, Madrid, 1981, y, posteriormente, «La autonomía local en la Constitución», en la obra colectiva Tratado de Derecho Municipal, I, Civitas, Madrid, 1988.

${ }^{14}$ Los Cabildos Insulares de Canarias son instituciones que, junto con la Real Audiencia, la Sede Episcopal y el Tribunal de la Inquisición, proceden de los siglos xv y xvI. Su régimen actual tiene su origen en la Ley de Cabildos de 1912, anterior, pues, a la división del archipiélago en dos Provincias en 1927. La Ley de Régimen Local, texto refundido de 24 de julio de 1955, mantuvo las características que en ese momento presentaba el régimen local en Canarias, pero incluyendo en el título referido a las Provincias y la organización provincial el sistema de Cabildos Insulares, a los que calificaba precisamente de <<órganos de administración propia > (art. 210), lo que explica su configuración en ella como organizaciones de segundo grado igual que las Diputaciones provinciales (art. 228, en su redacción inicial y también en la resultante del Decreto 406/1964, de 22 de febrero, que desarrolló la Ley 167/1963, de 2 de diciembre, modificatoria de la Base 38 de la Ley de 17 de julio de 1945).Tras la previsión por la Base 19. ${ }^{a}$ de la Ley 41/1975, de 19 de noviembre, de bases del estatuto de régimen local, nunca desarrollada, del establecimiento para el Archi-
} 
caso, al tiempo del proceso constituyente, es decir, del mencionado reconocimiento constitutivo la representatividad directa o de primer grado formaba parte ya de la imagen establecida de ambas instituciones insulares.

c) Es una entidad dotada, al igual que la Provincia (y que los Municipios), de autonomía para la gestión de los correspondientes intereses. La caracterización de la administración insular como propia no puede tener otro significado, en efecto, que su necesaria construcción sobre el principio de autonomía. Pues propia se contrapone a ajena y excluye así toda situación de heteronomía. En todo caso esta interpretación es la que mejor se corresponde con la pertenencia de la Isla al género Administración local, que en la norma fundamental se construye enteramente - a partir de la configuración de las dos instancias principales que la integran - sobre el referido principio de autonomía.

La garantía constitucional de la Isla como entidad territorial local necesaria en los Archipiélagos canario y balear, institucionalizadora de la correspondiente colectividad insular para la gestión, propia o con autonomía, de sus intereses y derivada del reconocimiento constitutivo de las formas organizativas existentes: Cabildos y Consejos Insulares, forma parte sin duda del modelo general de organización territorial del Estado que

piélago canario de un régimen administrativo especial adecuado a su carácter insular y respetuoso con las peculiaridades vigentes, la Ley 39/1978, de 17 de julio, de elecciones locales, y el Real Decreto 1169/1983, de 4 de mayo, dictado en su desarrollo, primero, y luego ya definitivamente la Ley Orgánica 5/1985, de 19 de junio, de régimen electoral general, articularon los Cabildos como organizaciones de representación directa, quedando integrados en el régimen local básico dentro del título referido a la Provincia y en calidad de <<régimen especial $>>$ por el artículo 41.1 de la LRBRL.

Los Consejos Insulares de las Islas Baleares son, por el contrario, instituciones coetáneas al proceso de transición a la democracia. Impulsada su creación fundamentalmente desde la Isla de Menorca al amparo de la Base 19. a. 3 de la Ley 41/1975, de 19 de noviembre, de bases del estatuto de régimen local, nacen con la creación del organismo preautonómico Consejo General Interinsular por Decreto-Ley 18/1978, de 13 de junio, y la previsión de su constitución por la Ley, ya citada, 39/1978, de 17 de julio, de elecciones locales, y el Real Decreto 1169/1983, de 4 de mayo, dictado en su desarrollo. Su régimen actual descansa en las pertinentes previsiones del EAIB y su integración en el régimen local básico en parecidos términos a los antes expuestos para los Cabildos Insulares (art. 41.3 LRBRL), encontrándose establecido por la LbCI00, derogatoria del primer texto regulador de los Consejos, la Ley balear 5/1989, de 23 de abril. Desde su mismo origen los Consejos Insulares han sido configurados como organizaciones de representación directa.

Sobre el proceso de creación y la evolución de los Consejos Insulares, véase B. CoLOM PASTOR, «La preautonomía de Las Islas Baleares y el futuro de los órganos provinciales locales en las Comunidades Autónomas uniprovinciales», capítulo IV de la obra Veinticinco años de autonomía balear. Estudios jurídicos sobre el autogobierno (1977-2000), Govern de les Illes Balears-Marcial PonsUniversitat de les Illes Balears, Madrid 2001. 
define directamente la Constitución e integra, así, un claro límite tanto para la autoorganización de las Comunidades Autónomas, como para el legislador, general y autonómico, de régimen local.

\section{La Isla en el EAIB}

Conforme a su preámbulo, el entero Estatuto $<<\ldots$ se fundamenta en el principio de cooperación entre los pueblos que forman la comunidad insular por vías de solidaridad, aproximación y respeto mutuo, que hacen posible una vida colectiva en armonía y progreso $>>$. El pluralismo territorial que impone el hecho insular y la consecuente existencia de $<<$ pueblos insulares $>>{ }^{15}$, que confiere carácter $<<$ compuesto $>>$ al pueblo y la comunidad política superior baleares (a los que se hace referencia igualmente en el preámbulo), están, pues, en la misma base del orden estatutario. Así lo corrobora la exposición de motivos de la Ley orgánica 3/1999, de 8 de enero, de modificación del EAIB, que califica ésta como $<<$ un punto y seguido $>>$, más que un $<<$ punto y final $>>$, en $<<\ldots$ las aspiraciones de autogobierno de los pueblos de Mallorca, Menorca e Ibiza y Formentera ... que permita continuar trabajando en adelante para alcanzar la cuota de participación política que en razón de nuestra historia nos corresponde>>.

\subsection{Las disposiciones estatutarias generales}

Es congruente con tales declaraciones que entre las disposiciones generales del EAIB (título primero) figuren las siguientes:

a) La determinación del territorio de la Comunidad Autónoma como la suma del de las islas mayores y menores que forman el Archipiélago (art. 2).

b) La habilitación a cada Isla para contar con símbolos distintivos propios, incluida la bandera (art. 4.2).

c) La articulación de la organización territorial de la Comunidad Autónoma en Islas y Municipios, cuyas instituciones de gobierno son,

\footnotetext{
${ }^{15}$ La constitucionalidad, más allá de lo que impone el Estado autonómico, de esta diferenciación de pueblos en el seno del pueblo español al que hace referencia el artículo 1.2 $\mathrm{CE}$, no parece que pueda ofrecer duda siempre que no implique cuestionamiento ni afectación algunas de la reserva al pueblo español en su conjunto del poder constituyente. Así lo ha razonado el autor en otro lugar: L. PAREJo Alfonso, «Cultura y Descentralización», Actas del Primer Congreso Iberoamericano de Derecho de la Cultura, pendiente de publicar.
} 
respectivamente, los Consejos Insulares y los Municipios; instituciones, cuya regulación corresponde, en el marco de la legislación básica del Estado, a una Ley del Parlamento de las Islas Baleares de acuerdo con el propio EAIB y los principios de eficacia, jerarquía, descentralización, desconcentración, delegación y coordinación entre los organismos administrativos y de autonomía en sus ámbitos respectivos (art. 5).

d) La fijación de una precisa orientación, en el desarrollo de sus funciones, a las instituciones de autogobierno, concretamente la de consolidación y desarrollo tanto de las características comunes de nacionalidad de los pueblos de Mallorca, Menorca, Ibiza y Formentera, como de las peculiaridades de cada una de éstas como vínculo de solidaridad entre todas las islas (art. 9).

Confirmando la afirmación del preámbulo del EAIB, la comunidad que se constituye — dotada ciertamente de identidad propia - se reconoce a sí misma compleja y plural por integrada por pueblos diferenciados (con peculiaridades propias) correspondientes a comunidades insulares. Dos de los elementos básicos de la Comunidad Autónoma, en tanto que instancia territorial, se determinan, en efecto, por relación a los territorios y las poblaciones insulares. La isla es, así, pieza decisiva en la organización territorial autonómica, pero en calidad de realidad propia, diferenciada desde luego de la autonómica propiamente dicha: conforme al artículo 5 EAIB, y en lo que aquí interesa, los Consejos Insulares no son instituciones de autogobierno autonómico en sentido estricto, sino cabalmente <<instituciones de gobierno de las islas $>>$, cuya regulación se remite, por ello, a un grupo normativo específico, inequívocamente distinto del propio de la referida a las aludidas instituciones de autogobierno. Así es porque la Ley autonómica que regule la organización territorial autonómica en su conjunto o alguna de sus piezas y, desde luego, la insular:

- Tiene exclusivamente por objeto <<organismos administrativos $>>$ en su propio ámbito de actuación distinto del de los organismos de la autonomía propiamente dicha o configurada por el EIAB (según el inciso final del art. 5.2 EAIB), y

- Ha de i) conformarse a los principios constitucionales definitorios del estatuto esencial de la Administración pública en su conjunto (los del art. 103.1 CE que reproduce y amplía el art. 5 EAIB) y el EAIB; y ii) insertarse en el marco de la pertinente legislación básica del Estado (cosa esta última que no sucede en modo alguno, por 
razones obvias, con la regulación legal de las instituciones del autogobierno autonómico en sentido estricto).

Estas disposiciones estatutarias son plenamente consistentes con el orden constitucional antes analizado, pues:

1. ${ }^{\circ}$ Determinan la Isla como instancia de la organización territorial de la Comunidad Autónoma, que no es, a su vez, sino parte componente de la del Estado a que se refiere el artículo $137 \mathrm{CE}$, sin que la relevancia que se le otorga - reflejo lógico de las características propias, es decir, las peculiaridades de la Comunidad Autónomapueda llegar a valorarse como desbordamiento alguno del orden constitucional.

2. ${ }^{\circ}$ Configuran la Isla, en cuanto organización, como institución de autogobierno administrativo de los intereses insulares, es decir, de modo congruente con la imagen asumida en la correspondiente garantía constitucional, que lo es de una manifestación específica de la Administración local.

3. ${ }^{a}$ Precisa el sistema de fuentes de la organización y el funcionamiento de la entidad administrativa Isla en términos enteramente fieles a su prefiguración por la norma fundamental del bloque de la constitucionalidad de referencia para el legislador autonómico: Constitución (de modo implícito), EAIB y legislación básica general-estatal.

\subsection{Las disposiciones relativas a las competencias autonómicas}

Las disposiciones generales estatutarias examinadas son de indudable trascendencia para la correcta interpretación de las competenciales de que ahora se trata y que, en lo que interesa, distinguen entre competencias exclusivas, entendidas como aquéllas comprensivas del entero ciclo de la gestión de los asuntos públicos en la materia correspondiente (legislación y ejecución) sin otro marco de referencia, en principio, que la Constitución desde luego y el EAIB [las del artículo 10], de un lado, y competencias de desarrollo legislativo y ejecución, entendidas como aquéllas que deben ser ejercidas en el marco no solo de la Constitución y el EAIB, sino también de la legislación básica dictada en la materia correspondiente por las instituciones generales del Estado [las del artículo 11], de otro lado. Pues la competencia para el dictado de la Ley autonómica a que remite el ya comentado artículo 5 EAIB no puede pertenecer sino a las segundas, es decir, las enumeradas en el artículo 11 de éste. 
La organización, el régimen y el funcionamiento de $<<$ sus $>>$ instituciones de autogobierno (de la Comunidad Autónoma) es, en tanto que materia <<estatutaria〉> según el artículo 147.2 , c) CE, también materia objeto de una de las competencias exclusivas del artículo 10 EAIB, es decir, ejercitable teniendo como único marco de referencia a la Constitución.

Entre las competencias autonómicas que han de ejercitarse en el marco, además de la Constitución y el EAIB, de la legislación básica general-estatal no aparece, por el contrario, ninguna consistente en la organización territorial de la Comunidad, la organización y el funcionamiento de los Municipios y los Consejos Insulares o el régimen, organización y funcionamiento de estos últimos. Aparecen, por el contrario, cuatro materias que, sumadas, pretenden sin duda acotar el conjunto de las enunciadas en el artículo 149.1.18. ${ }^{a} \mathrm{CE}$ en que la Comunidad Autónoma asume el desarrollo legislativo y la ejecución:

a) En tres de ellas, referidas, respectivamente, al régimen de la responsabilidad de la Administración de la Comunidad Autónoma y de la Administración local (regla 1. ${ }^{a}$ del art. 11 EAIB), el estatuto de los funcionarios de la Administración de la Comunidad Autónoma y de la Administración local (regla 4. ${ }^{a}$ del art. 11 AEIB) y las normas procesales y de Derecho administrativo derivadas de las peculiaridades del Derecho sustantivo de las Islas Baleares o de las especiales de la organización de la Comunidad Autónoma (regla 3. ${ }^{\mathrm{a}}$ del art. 11 EAIB), queda clara la diferenciación y separación netas de la Administración de la Comunidad Autónoma y la Administración local, por mas que ambas queden sujetas desde luego a la legislación básica general-estatal dictada al amparo del artículo 149.1.18 CE; separación, que es acorde con el bloque de la constitucionalidad al que, como ya ha quedado establecido, ha de ajustarse el legislador autonómico.

Pues la proyección — en efecto cruzado - de la potestad autoorganizativa de la Comunidad Autónoma sobre la regulación de la Administración pública al interior de dicha Comunidad presenta obviamente diverso grado de intensidad según se trate del establecimiento del régimen de la Administración $<<$ propia $>>$ de ésta (mayor en este caso, al tratarse del autogobierno autonómico en sentido estricto) o de la definición del régimen de las entidades de la Administración local (menor en este caso, con independencia de la relevancia estatutaria de alguna de dichas entidades, al tratarse de la normación del autogobierno de éstas y no del autonómico).

b) En la cuarta, identificada como <<régimen local $>$ (regla 2. ${ }^{\text {a del art. }}$ 11 EAIB), se hace presente, teniendo en cuenta el contenido de las tres 
anteriores, que el EAIB i) parte de la inclusión del régimen (entendido como suma de organización y funcionamiento) de la Administración propia de la Comunidad Autónoma (excepción hecha de los aspectos relativos a la responsabilidad patrimonial y al estatuto de la función pública) en la materia organización de la Comunidad Autónoma y, más concretamente, $<<$ organización, régimen y funcionamiento de sus instituciones de autogobierno $>>$ a que se refiere la regla $1 .^{a}$ del artículo 10 del propio EAIB; $y$, en consecuencia, ii) acota la que ahora se trata como comprensiva del régimen de todas las organizaciones administrativas distintas de la anterior y que no pueden ser otras que las integrantes de la organización territorial de la Comunidad antes estudiada, con el resultado evidente del tratamiento de las mismas como manifestaciones de la Administración local.

Conforme al EAIB, pues, el legislador autonómico que regule la organización territorial de la Comunidad Autónoma o cualquiera de sus dos instancias territoriales, la municipal y la insular, no puede ser otro que el que ejercite precisamente la competencia asumida en materia de régimen local.

Se desprende sin más, con toda naturalidad, de lo dicho, la coherencia de estas disposiciones competenciales con las generales, ambas del EAIB, $\mathrm{y}$ de ellas con el orden constitucional.

\subsection{La regulación estatutaria de las instituciones de la Comunidad Autónoma}

La sistemática interna del título III del EAIB, relativo a las instituciones de la Comunidad Autónoma de las Islas Baleares, es esencial para la correcta comprensión de su contenido dispositivo.

Al igual que sucede con el artículo 10 en el caso del titulo primero de la Constitución, el artículo 18 de este título estatutario está colocado antes y fuera de la subdivisión de dicho título en capítulos. Se trata, pues, de un precepto clave, en cuanto, extendiendo desde luego su radio de acción al entero título, define acabadamente el cuadro institucional autonómico objeto a continuación de desarrollo separado y pormenorizado (por capítulos).

Gracias a él adquiere sentido en el sistema estatutario, en cuanto unidad, la puramente aparente contradicción con las disposiciones hasta ahora estudiadas que parece representar la dedicación a los Consejos Insulares de un capítulo (el cuarto) y, por tanto, un tratamiento formalmente equi- 
valente al Parlamento (capítulo primero), el Presidente (capítulo segundo), el Gobierno (capítulo tercero), el Consejo Consultivo (capítulo quinto) y la Administración de la Comunidad Autónoma (capítulo sexto).

La división interna del artículo 18 EAIB en dos números referidos respectivamente a $<<$ la organización institucional autonómica $>>$, el primero, y los Consejos Insulares, el segundo, no es, en efecto, ni casual, ni puramente formal, ni, por tanto, en modo alguno intrascendente. El tenor literal del número uno del precepto no deja lugar a duda alguna sobre el carácter taxativo y agotador de la enumeración de instituciones propiamente autonómicas que realiza: el Parlamento, el Presidente y el Gobierno son las únicas instituciones de autogobierno de la Comunidad Autónoma en sentido estricto que crea y define el Estatuto de Autonomía en el ejercicio del derecho reconocido en el artículo $2 \mathrm{CE}$ que formaliza conforme al artículo $147 \mathrm{CE}$ y, concretamente, su número $2, \mathrm{c})^{16}$.

El número 2 del artículo 18 EAIB alude a los Consejos Insulares, en efecto, no como instituciones del autogobierno autonómico, sino - de modo coherente con toda regulación estatutaria hasta aquí estudiadacomo instituciones:

a) A las que corresponde <<el gobierno y la administración $>>$ de las correspondientes islas.

La diferencia con la caracterización de los órganos enunciados en el número 1 del mismo precepto estatutario salta a la vista: éstos son elementos integrantes de la <<organización institucional autonómica >>, condición organizativo-subjetiva de la que, en consecuencia carecen los Consejos Insulares.

\footnotetext{
${ }^{16}$ Esta enumeración no es contradictoria con la dedicación de un capítulo propio a la Administración de la Comunidad Autónoma. Al igual que sucede con la regulación del complejo GobiernoAdministración en el texto constitucional, la enumeración de instituciones que lleva a cabo el artículo 18 EAIB supone incluida dicha Administración a través del Gobierno. Pues es claro, como resulta de sus artículos 32.1 y 35, que el Estatuto de Autonomía concibe la Administración autonómica como infraestructura del Gobierno para el adecuado desarrollo por éste de sus funciones ejecutiva y administrativa y, por tanto, aquélla como prolongación, en otro plano (organización subordinada y dirigida), de éste, formando ambos un complejo orgánico-funcional (el Gobierno y la Administración a que se refiere el artículo 35 EAIB ya citado) en el que la pieza relevante, desde el punto institucional y del autogobierno, es precisamente el Gobierno. Ello explica la no mención expresa y separada de la Administración propia en el artículo 18 EAIB. Pero al propio tiempo justifica el tratamiento que en el título tercero de la norma estatutaria se da a la Administración autonómica.
}

Razonamiento en todo análogo vale para el paralelo tratamiento específico que en el mismo título de la norma estatutaria recibe la organización consultiva y de asesoramiento (el Consejo Consultivo de las Islas Baleares y el Consejo Económico y Social de las Islas Baleares). 
b) A constituir en los términos y con las competencias que resultan de la Constitución y el EAIB.

Es significativa la mención aquí, junto con el EAIB, de la Constitución, pues ambas forman, como ya ha quedado visto, el núcleo esencial del bloque de la constitucionalidad a observar por la legislación autonómica reguladora de la organización, régimen y competencias de los Consejos Insulares.

Luce en el artículo 18 EAIB, así, el empleo anfibológico de la noción $<<$ Comunidad Autónoma $>>{ }^{17}$, que unas veces designa a la entera y plural comunidad político-administrativa que se constituye precisamente mediante el Estatuto de Autonomía ${ }^{18}$ y otras hace lo propio únicamente respecto del conjunto de instituciones de autogobierno autonómico en sentido estricto. En otras palabras: en el primer caso significa la Comunidad Autónoma-comunidad y en el segundo la Comunidad Autónoma-organización.

Al igual que sucede con el Estado, la Comunidad Autónoma de las Islas Baleares, en cuanto comunidad político-administrativa, tiene tanto una expresión subjetivo-organizativa, como una organización territorial (cabalmente la perfectamente definida en el EAIB y antes estudiada). Los Consejos Insulares son así, pues, Comunidad Autónoma, en tanto que instancias de la organización territorial de ésta, pero no parte del sujeto-organización autonómico. No son, en suma, instituciones del autogobierno autonómico.

Lo corroboran concluyentemente, teniendo en cuenta la indiscutible condición de Administraciones de los Consejos Insulares, las siguientes disposiciones estatutarias:

1. ${ }^{\text {a }}$ Por de pronto, la expresa exclusión de dichos Consejos Insulares de la $<<$ Administración propia $>>$ de la $<<$ Comunidad Autónoma $>>$ (aquí alusiva a la Comunidad-organización) prevista en el artículo 43 EAIB, toda vez que ésta última - por imperativo del artículo 44 EAIB — ha de ejercer sus competencias administrativas a través de $<<$ los entes y los

\footnotetext{
${ }^{17}$ Se trata de la misma anfibología presente en el empleo por la Constitución de la noción de $<<$ Estado >>, que, como ha tenido ocasión de establecer la doctrina del Tribunal Constitucional, unas veces alude a la entera comunidad política constituida (el entero Estado del artículo 1.1. CE o Estado en sentido lato) y otras tan sólo se refiere al conjunto preciso de instituciones generales que ejercen las competencias que al Estado en sentido estricto reserva el artículo 149.1 y $2 \mathrm{CE}$.

${ }^{18}$ Comunidad de comunidades o pueblos insulares, según las disposiciones generales del EAIB, como ya ha quedado establecido.
} 
organismos dependientes del Gobierno de las Islas Baleares $>>$, de los que no forman parte los Consejos Insulares, que aparecen mencionados aparte y junto con los Municipios.

\section{2. ${ }^{\text {. }}$ La regulación misma de los Consejos Insulares.}

La definición de éstos no deja lugar a duda, en la medida en que — referidos exclusivamente al gobierno, la administración y la representación de las correspondientes islas-:

a) Se les reconoce autonomía en la gestión de sus intereses (art. 36 EAIB), lo que significa que: i) constituyen expresión organizativa de la pertinente colectividad o comunidad insular (diferenciada de la autonómica en el seno de ésta, así como también de la general-estatal); y ii) no pueden equipararse a entes dependientes del Gobierno de las Islas Baleares.

Con esta autonomía sustantiva se corresponde el reconocimiento a los propios Consejos Insulares de autonomía financiera basada en el principio de suficiencia de este carácter y sobre la base de la existencia exclusivamente de dos Haciendas: la autonómica y la local, cuyos recursos — por lo que hace a la instancia insular - aparecen enumerados y diferenciados de los de la Hacienda autonómica (art. 68, en relación con los arts. 58.1 y 69, todos ellos del EAIB).

b) El marco de su legislación propia aparece definido en términos prácticamente coincidentes con los del artículo 5.2 EAIB y plenamente conformes, en todo caso, con el que resulta de la Constitución (art. 36 EAIB).

c) Sus competencias aparecen integradas desde luego y en primer lugar por las que les correspondan en su calidad de Corporaciones locales, si bien a ellas se añaden las que puedan resultar de la facultad que se les otorga de asumir, para su ámbito territorial, la función ejecutiva y la gestión en un listado de materias (las del art. 39 EAIB), en la medida misma en que la Comunidad Autónoma (de acuerdo con la lógica y la economía del Estado autonómico) haya asumido competencias suficientes en tales materias.

De donde se sigue el reconocimiento estatutario expreso de la condición de Administraciones locales de los Consejos Insulares, sin perjuicio de la decisión de incrementar la esfera competencial (posible) de éstos sobre la delimitada con carácter general por la legislación de régimen local. Esta decisión ni enerva, ni desmiente, ni modula en modo alguno aquella condición de entidades locales, pues la cantidad e intensidad de las competencias (siempre puramente administrativas) no pueden transmutar por sí solas la naturaleza del sujeto titular de ellas. De otro lado, el meca- 
nismo mismo previsto para la <<ampliación $>>$ de la esfera competencial insular así lo confirma. Pues reproduce, adaptándolo a la escala interna autonómica y a las características de las instancias autonómica e insular, el establecido para la descarga de competencias desde el Estado-organización o en sentido estricto en las Comunidades Autónomas.

d) Se predetermina su régimen jurídico en términos un tanto confusos, pero que implican la reserva en principio al Gobierno de las Islas Baleares de la potestad reglamentaria ad extra, salvo cuando ésta esté atribuida a los Consejos Insulares por Ley general-estatal o Ley autonómica (art. 49 EAIB) en el contexto de la regulación de las competencias exclusivas autonómicas, confirmando de esta suerte la diferenciación entre las instancias autonómica e insular y la reducción de ésta al ámbito administrativo.

e) Se les sujeta, por lo que hace a su entera actividad (sin distinción en función de tipología alguna de las competencias ejercitadas en dicha actividad $^{19}$ ) a la coordinación del Gobierno de las Islas Baleares, como gestor de los intereses autonómicos y órgano superior de la Administración $<<$ comunitaria $>>$ (art. 40 EAIB).

Esta previsión es una lógica consecuencia del reconocimiento de la autonomía de los Consejos Insulares y expresa la no dependencia de éstos respecto del Gobierno de las Islas Baleares y de la Administración autonómica por el dirigida.

Esta regulación acredita ya definitivamente que los Consejos Insulares no son estrictamente instituciones de autogobierno autonómico, en la medida en que no están, como éstas, en la plena disposición de la potestad de autoorganización autonómica (únicamente limitada por la Constitución). No es que escapen a esta potestad, es que el margen decisional que, en ejercicio de ésta, cabe a la hora de la ordenación legal de los Consejos Insulares aparece más intensamente circunscrito: limitado, desde el contexto más amplio del entero Estado, por la Constitución y el modelo de Administración pública general y de Administración local en concreto definido en desarrollo de ésta; y limitado por ello mismo también desde la institución insular misma, en tanto que dotada ésta en aquel contexto de una imagen característica imposible de desconocer o desfigurar ya en sede del autonómico.

\footnotetext{
${ }^{19}$ La única diferenciación que se hace tiene por objeto permitir, cuando de competencias atribuidas por una Ley del Parlamento de las Islas Baleares se trata (acotación que no necesariamente coincide con la distinción entre competencias con origen en la legislación de régimen local y competencias con origen último en el artículo $39 \mathrm{EAIB}$ ), el establecimiento caso a caso de formas de control y coordinación reservadas al Gobierno de las Islas Baleares.
} 


\subsection{La determinación estatutaria de los Consejos Insulares como instituciones locales específicas o de trascendencia autonómica}

La organización territorial de las Islas Baleares en tanto que comunidad político-administrativa no es, así, sino trasunto del pluralismo interno de ésta como $<<$ comunidad de comunidades insulares $>>$. Esta peculiaridad es la que está en la base de la específica modulación, ya en sede estatutaria y en sede de la autoorganización autonómica, de la instancia insular, por diferencia con el tratamiento de que es objeto la instancia municipal. Se trata de una modulación perfectamente constitucional, según se ha razonado ya, en tanto que fruto legítimo de la proyección de la potestad de autodisposición de la Comunidad Autónoma sobre si misma en el marco de la Constitución.

De esta suerte, la Isla es ciertamente una comunidad y una organización diferenciada en el seno de la Comunidad Autónoma, pero dotada en ella de un status especial. Este status alcanza su manifestación más llamativa e intensa en la organización misma de los Consejos Insulares. Pues se integran cabalmente, conforme al artículo 37 EAIB, por los Diputados elegidos para el Parlamento por las correspondientes circunscripciones insulares, de suerte que los representantes de los pueblos insulares y gestores (administrativos) de sus intereses son al propio tiempo los representantes del pueblo balear en su conjunto y ejercientes de la función legislativa para todo él. La fórmula es plenamente congruente con el auto-reconocimiento de la Comunidad Autónoma como $<<$ comunidad de comunidades insulares $>>$ identificada por los elementos comunes aglutinantes y no negadores de las particularidades de las que la componen.

Se entiende, pues, que los Consejos Insulares se configuren desde luego, en cuanto organizaciones, como Administraciones locales gestoras con autonomía de los intereses de las correspondientes comunidades, pero dotadas en el plano funcional-competencial de un papel específico en la gestión de los intereses materialmente autonómicos (como resulta de los arts. 5 y 18.2, en relación con el art. 39 EAIB). Pues dada la configuración misma de la comunidad político administrativa constituida estatutariamente dichos intereses y los propiamente insulares aparecen profundamente imbricados, lo que no sucede con los intereses estrictamente municipales. Se explica plenamente de esta forma el tratamiento sistemático que el EAIB da a los Consejos Insulares en su título III referido globalmente a las instituciones de la entera Comunidad Autónoma, al cual no cabe otorgarle una significación jurídica distinta de la que con naturalidad resulta de lo dicho. Pues el aludido tratamiento expresa, en correspondencia con la articulación descentralizada de la organización territorial de la 
Comunidad Autónoma, la trascendencia autonómica, en el plano funcional, de las instancias insulares, que no por ello dejan de ser lo que son desde la Constitución: Administraciones locales.

No precisa mayor argumentación alguna la afirmación de la plena conformidad con la Constitución del grado de <<interiorización $>>$ de los Consejos Insulares (en ejercicio de la potestad autonómica de autoorganización) que resulta de las consideraciones precedentes.

\section{La Isla en la legislación básica de régimen local}

Como no podía ser de otra forma, la Ley 7/1985, de 2 de abril, reguladora de las bases del régimen local, de acuerdo con el orden organizativo constitucional antes expuesto, equipara las Islas a las Provincias en cuanto a la calidad de entidades locales territoriales dotadas del elenco de potestades propio de tal condición y, por ello, de la autonomía garantizada constitucionalmente por igual a todas aquellas entidades a los efectos de la gestión de sus intereses propios respectivos (arts. 1.2, 2.1, 3.1 y 4.1).

La organización de las Islas aparece en el régimen local básico, por ello (la perspectiva que otorga la aludida equiparación, propiciada desde el artículo $141 \mathrm{CE}$ ), en el título tercero referido a la Provincia dentro del capítulo dedicado significativamente a los $<<$ regímenes especiales $>>$ y junto con a la regulación dedicada a los órganos forales de Álava, Guipúzcoa y Vizcaya (art. 39) y a la integración funcional del círculo de intereses provinciales en el de las correspondientes Comunidades Autónomas cuando de las uniprovinciales y de la foral de Navarra se trata (art. 40). Un mismo artículo, el 41, aborda los Cabildos Insulares de las Islas Canarias y los Consejos Insulares de las Islas Baleares, es decir, la organización insular en los territorios archipielágicos.

Mientras en el caso canario la existencia de dos Provincias con una bien consolidada estructura administrativa insular conduce a la reducción de la expresión institucional local de éstas a un órgano específico provincial con función limitada a la representación y expresión de los intereses provinciales y, por ello, a la plena correspondencia de las Islas con la Provincia continental (del círculo de intereses que en la organización territorial continental es propio de ésta con el propio de la Isla en el archipiélago canario), es decir, de los Cabildos a las Provincias ${ }^{20}$, en el caso balear la solu-

\footnotetext{
${ }^{20}$ De ahí que el artículo 41.1 LrBRL determine taxativamente que los Cabildos $\ll<\ldots$ se rigen por las normas de esta Ley que regulan la organización y funcionamiento de las Diputaciones provin-
} 
ción es distinta, sin duda por tratarse de un territorio uniprovincial constituido en Comunidad Autónoma con una configuración estatutaria que singulariza la función y, consecuentemente, las competencias de la instancia insular, vinculada ella misma al proceso de acceso a la autonomía. Lo corrobora plenamente el inciso final del artículo $41 \mathrm{LrBR}$ — referido cabalmente a la solución para la instancia provincial en la Comunidades Autónomas uniprovinciales-, en cuanto exceptúa de dicha solución cabalmente a la Comunidad Autónoma de las Islas Baleares $<<$ en los términos de su Estatuto propio $>$. Es claro, pues, que la LrBRL se muestra sensible a la pieza estatutaria del bloque la constitucionalidad en cuyo marco se mueve y que ella misma acaba de integrar respecto del legislador autonómico en un momento en que éste no se ha pronunciado aún. De ahí que el número 3 de su artículo 41:

a) Emplee para los Consejos Insulares y en cuanto a su organización y funcionamiento la fórmula $<<$ son de aplicación las normas de esta Ley $>>$ y no la de $<<$ se rigen $>>$ utilizada para los Cabildos Insulares.

Esta mera <<proyección >> sobre los Consejos Insulares de las normas generales relativas a la Provincia ha de entenderse obviamente - en el contexto de la interpretación conjunta del artículo 41.3 y inciso final del artículo 40 LrBRL y teniendo en cuenta que ambos se inscriben en la regulación de los regímenes especiales $<<$ provinciales $>>$ o mejor supramunicipales y que ésta, por definición no puede tener menor alcance que la de los regímenes municipales asimismo previstos en la LrBRL- como fórmula susceptible de considerable $<<$ desplazamiento $>>$ por la legislación autonómica específica, en tanto que legislación no solo de desarrollo, sino de concreción de la autoorganización de la Comunidad Autónoma por lo que hace a su organización territorial.

b) Modula perfectamente la determinación del espacio competencial insular, al señalar que los Consejos Insulares $<<$ asumen sus competencias de acuerdo con lo dispuesto en esta Ley y las que les correspondan de conformidad con el Estatuto de Autonomía de Baleares $>>$. Nótese, en efecto, que, a diferencia de los Cabildos Insulares, no dice que los Consejos Insulares asuman las competencias de las Provincias, sino que asumen sus competencias (las de los propios Consejos) de acuerdo con lo dispuesto en el texto legal, es decir, con el sistema de atribución de competencias dispuesto para las Provincias, aludiendo a las competencias como tales únicamente por relación a las previstas en el Estatuto de Autonomía.

ciales, asumiendo las competencias de éstas, sin perjuicio de las que les corresponden por su legislación específica > (la cursiva es del autor). 
Es claro, pues, que el legislador básico es consciente de la especificidad de los Consejos Insulares (en cuanto instituciones locales de nuevo cuño) y respetando así su imbricación, desde su mismo origen, en el autogobierno balear, ratifica de modo flexible su condición de entidad local: en lo organizativo y de funcionamiento mediante la extensión —en los términos indicados- de las reglas propias de la entidad provincial y en lo competencial mediante el expediente de hacer a la instancia insular receptora, por igual, de las atribuciones que resulten de la lógica propia tanto del régimen local como del régimen estatutario autonómico.

Siendo obvia no es necesario insistir en la perfecta adecuación al bloque de la constitucionalidad y, en particular, al EAIB, de la solución competencial: la descarga competencial que desde aquél y en los Consejos Insulares quiera hacer en cada momento la Comunidad Autónoma en función de la política propia que defina a partir de su específica organización territorial, encuentra en dicha solución holgado y perfecto encaje. Pero tampoco la solución organizativa de aplicación, la prevista para las Diputaciones, implica impedimento a la proyección legítima en tal campo de la potestad de autoorganización de la Comunidad Autónoma. Y ello ya desde la versión original de la LrBRL, tanto más aun desde su modificación parcial en 1999 en virtud del denominado pacto local, y ateniéndose incluso al régimen local general. En efecto:

a) La organización provincial aplicable está ciertamente integrada por un conjunto de órganos necesarios (el Presidente, los Vicepresidentes, la Comisión de Gobierno y el Pleno, según el art. 32, regla 1. a), pero la totalidad de los restantes órganos posibles (complementarios en la terminología de la LrBRL) quedan entregados sin mayor predeterminación a la legislación autonómica y al Reglamento Orgánico propio de cada entidad (aquí los Consejos Insulares) [art. 32, regla 2. ${ }^{a}$ ], tanto más cuanto que el régimen básico así aplicable a estos Consejos es <<especial >> y, por tanto, salvado expresamente de la prohibición de regulaciones singulares para las entidades locales que contiene el artículo 9 LrBRL.

El juego de la legislación autonómica, amplio ya en la versión original de la Ley una vez depurada su constitucionalidad por la Sentencia del Tribunal Constitucional de 21 de diciembre de $1989^{21}$, lo es más aún en la

\footnotetext{
${ }^{21}$ Sabido es que el texto aprobado por las Cortes reservaba el entero espacio de autoorganización definido desde el régimen básico a favor de la autoorganización de cada entidad (a través del correspondiente Reglamento Orgánico), quedando la legislación autonómica en este concreto punto en posición secundaria. La Sentencia del Tribunal Constitucional de 21 de diciembre de 1989 corrigió esta opción en el sentido de afirmar para la legislación autonómica, también en el
} 
actualidad, tras la Ley 11/1999, de 21 de abril. Pues en la redacción dada por ésta a la regla $2 .^{\text {a }}$ del artículo 32 LrBRL, aquella legislación autonómica queda habilitada en general para establecer por si misma la pertinente organización complementaria, pero, además y para un concreto ámbito de la misma (el relativo a la preparación de los asuntos del Pleno y el seguimiento y control de la gestión de los restantes órganos necesarios), para prever $<<$ una forma organizativa distinta $>>$ (se entiende a la básica).

b) La organización necesaria se encuentra hoy, de otro lado y en cuanto definitoria del <<sistema de gobierno y administración $>>$ provincial y, por extensión, insular, matizada justamente por la introducción de la comentada organización complementaria básica (pero desplazable en sede de desarrollo autonómico) atinente a la preparación de las decisiones plenarias y el seguimiento y control de la gestión de los órganos superiores ejecutivos. Pues con motivo de esa introducción se escora implícita pero claramente el centro de gravedad del sistema de gobierno y administración del lado de los órganos ejecutivos en detrimento del plenario deliberante. Así resulta de la previsión de órganos de seguimiento de la gestión del Presidente, la Comisión de Gobierno y los Diputados (Consejeros) que ostenten delegaciones $<<\ldots$ sin perjuicio de las competencias de control que correspondan al Pleno $>$.

c) La determinación de la organización básica se complementa ciertamente con un reparto de competencias entre los dos principales órganos: el Pleno (art. 33) y el Presidente (art. 34). Pero además de que ese reparto ha sido innovado en la expresada línea de reforzamiento del ámbito competencial de la Presidencia ${ }^{22}$, ha de entenderse desde la lógica general del régimen básico: se trata de un reparto tipo ${ }^{23}$ que puede ser alterado, justamente en beneficio de la organización ejecutivo-administrativa, en sede incluso de la autoorganización de cada entidad (vía Reglamento Orgánico), mediante el empleo, en su caso combinado, de dos técnicas:

\footnotetext{
terreno de la organización interna, su posición general de norma legal de integración —a título de desarrollo de la básica — del régimen local delimitador de la autonomía de cada ente local.

22 Por la ya comentada Ley 11/1999, de 21 de abril.

${ }^{23}$ En el sentido de definitorio de la separación-equilibrio de funciones (con reflejo orgánico) de la economía y lógica propias del gobierno autónomo local. En modo alguno es refractario ese reparto, ni a su modulación por efecto del proceso de asignación concreta de competencias derivado de la acción de la legislación sectorial (acción a la que la LrBRL se muestra plenamente abierta), ni a la redistribución interna de competencias en virtud sea de desconcentración, sea de descentralización funcional, que no lo ponga en cuestión la expuesta economía y lógica del sistema de gobierno y administración (en otro caso carecería de verdadero sentido la remisión a la autoorganización mediante Reglamento Orgánico).
} 
- La delegación de competencias (del Pleno en el Presidente y la Comisión de Gobierno; y del Presidente en los miembros de la Comisión de Gobierno y, más limitadamente, en Diputados/Consejeros) que contemplan los propios artículos 33 y 34 LrBRL y que puede actuarse sin necesidad de previsión alguna otra.

- La desconcentración de competencias que, vía Reglamento Orgánico, puede disponer cada entidad y que en modo alguno está prohibida por el aludido reparto de competencias entre los dos órganos superiores principales de entre los necesarios. Téngase en cuenta que si se reconoce la autoorganización como facultad nuclear de la autonomía de cada entidad local, es posible desde luego la descentralización de competencias en entidades dependientes (descentralización funcional; art. 85.3 LrBRL) y se admite expresamente, incluso, la transferencia de competencias propias (funciones o actividades) a entidades distintas mediante acuerdo plenario adoptado por mayoría absoluta [art. 47.3, c) LrBRL], con mayor motivo - argumento de maiore ad minus - debe estar permitida la desconcentración de competencias en el seno de la propia organización. Tanto más cuanto que la desconcentración administrativa es principio de rango constitucional (art. 103.1), la aprobación del Reglamento Orgánico requiere el mismo quorum de votación que la transferencia de competencias [art. 47.3, a) LrBRL] y a resultado análogo en la práctica se puede llegar en cualquier caso por la vía de las delegaciones.

A las consideraciones anteriores se añaden aún las derivables de la conceptuación como especial (de los exceptuados por el artículo 9 LrBRl, como ya se ha adelantado, de la prohibición del establecimiento, en sede desarrollo, de regulaciones con ámbito de aplicación limitada a determinadas entidades con carácter singular) del régimen de los Consejos Insulares. Para hacer presente toda la significación de esta conceptuación basta con traer a colación i) la enorme amplitud de la habilitación que a la legislación autonómica de régimen local hace el artículo 30 para establecer - cabalmente en el marco de la LrBRL - regímenes especiales para Municipios pequeños o de carácter rural y para aquéllos que reúnan otras características que lo hagan aconsejable (como su carácter histórico-artístico o el predominio en su término de actividades turísticas, industriales, mineras u otras semejantes); y ii) el mantenimiento por la disposición adicional sexta de los regímenes especiales de los Municipios de Barcelona y Madrid, con previsión expresa en el segundo caso de su actualización por la Ley especial prevista por el artículo 6 del Estatuto de la Comunidad de Madrid. 


\section{LA CONFIGURACIÓN CONSTITUCIONAL DEL GOBIERNO Y LA ADMINISTRACIÓN LOCAL COMO AUTOADMINISTRACIÓN DEMOCRÁTICA Y LA VIGENTE ORGANIZACIÓN DE LA INSTANCIA INSULAR POR LA LbCI01}

Aunque como es lógico la Constitución no realiza una regulación mínimamente detallada de la organización del poder público administrativo ${ }^{24}$, prefigura éste como un complejo sistema que pivota sobre las Administraciones territoriales correspondientes a las instancias territoriales de la organización del entero Estado y, con este motivo, diseña dos principales tipos (ideales) diferenciados de $<<$ administración $>>$ (en el doble aspecto constructivo y funcional): el institucional-burocrático, en el que - siendo lo decisivo el desarrollo profesionalizado de las tareas y los cometidospriman los factores de legitimación atinentes a la corrección jurídica, la calidad técnica y material $y$, en definitiva, el resultado de la actividad administrativa misma objetivamente considerada ${ }^{25}$ (tipo éste al que responden las Administraciones incardinadas a los Gobiernos de las dos instancias superiores de la organización territorial del Estado, es decir, la Administración General del Estado y las Administraciones directas de las Comunidades Autónomas) y el de la autoadministración democrática, en el que adquiere primacía el valor de la participación directa o mediante representantes de los ciudadanos, considerados éstos, además, como $<<$ miembros $>>$ de la colectividad institucionalizada por la propia entidad administrativa y, en tal condición, <<titulares $>>$ últimos de los intereses públicos a gestionar mediante las tareas y los cometidos atribuidos a dicha entidad $^{26}$.

\footnotetext{
${ }^{24}$ En lo que hace a la Administración la atención del constituyente se centra en la dimensión funcional, estableciendo un estatuto principial de la actividad administrativa (arts. 103 y $106 \mathrm{CE}$ ), del que no está ausente, sin embargo, la organizativa. De todas formas, de la norma fundamental es deducible un elenco de tipos de organización administrativa en modo alguno establecido simplemente como conjunto de posibilidades de libre elección en cuanto relacionado con el complejo de factores de legitimación propio del Estado democrático y social de Derecho constituido. Sobre estos aspectos véase Luciano PAREJo Alfonso, «Gobierno y Administración pública en la Constitución española», en la obra colectiva dirigida por Jaime RodríGuEZ-ArANA, La Administración pública española, INAP, Madrid, 2002, p. 89 y ss.

${ }^{25}$ Sin que por ello dejen de tener importancia los factores ligados al principio democrático, que operan, sin embargo, básicamente a través de la imputación de la actividad administrativa in totum, en cuanto $<<$ dirigida $>>$ y $<<$ servicial $>>$, a la responsabilidad política del correspondiente Gobierno (cabeza de la Administración y director de la misma) ante el Parlamento pertinente.
}

${ }^{26}$ Sin que por ello tampoco en este caso dejen de operar los factores de legitimación más específicos de la actividad administrativa. 
Cabe decir, por ello, que la <<imagen >> de gobierno y administración locales garantizada constitucionalmente comprende desde luego la apuntada naturaleza de la gestión local como autoadministración democrática, circunstancia que permite el planteamiento de la cuestión de la posible desfiguración de tal imagen por la vigente regulación legal de los Consejos Insulares baleares, en la medida misma en que dicha regulación introduce con decisión en la organización $<<$ ejecutiva $>>$ de estos órganos unipersonales cuyos titulares no han de ser representantes de los $<<$ miembros $>>$ de la colectividad insular.

La $<<$ autoadministración>>, en cuanto implica la imputación de la gestión administrativa a los propios destinatarios, remite a la configuración, mediante su organización cabalmente administrativa, de la correspondiente realidad social (aquí la colectividad insular). La decisión constitucional que implica la garantía constitucional de las instituciones municipal, provincial e insular presupone ciertamente la existencia de las respectivas colectividades, pero constituye éstas en tanto que organizaciones parte del poder público administrativo del Estado. En este sentido Municipio, Provincia e Isla son organizaciones de configuración — principial— constitucional, por más que el legislador ordinario tenga un amplio margen a la hora del desarrollo de la norma fundamental. Guardan parentesco, así, con las Universidades ${ }^{27}$ y representan -en particular el Municipio-el modelo mismo de los demás fenómenos (meramente funcionales) que la doctrina del Tribunal Constitucional ${ }^{28}$ agrupa en la categoría de organizaciones de configuración legal, de entre las cuales destacan los Colegios Profesionales ${ }^{29}$.

Como se desprende de la regulación constitucional de esta última categoría de organizaciones, para inducir la legitimación considerada por la norma fundamental el tipo <<autoadministración>> requiere únicamente la posibilidad de imputación directa de la actividad de la organización a los miembros de ésta y destinatarios de aquélla; posibilidad que hace efectiva de suyo sin más la construcción democrática de tal organización y de su

\footnotetext{
${ }^{27}$ La dimensión organizativo-objetiva del artículo 27.10 CE es bien evidente.

${ }^{28}$ Sobre esta doctrina véase L. PAREJO ALFONSO, «Las organizaciones sociales de configuración legal a la luz de la doctrina del Tribunal Constitucional», estudio preliminar al libro de Silvia DEL SAz, Cámaras oficiales y Cámaras de Comercio, Marcial Pons, Madrid, 1996.

${ }^{29}$ Regulados específicamente en el artículo 36 CE. Junto a ellos, el artículo 52 CE se refiere genéricamente a las organizaciones profesionales para la defensa de los intereses económicos que les sean propios. Ambos preceptos constitucionales se limitan a imponer - como única exigencia derivada de la <<imagen $>>$ constitucional de la $<<$ autoadministración $>>-$ la condición democrática de la estructura y el funcionamiento de la correspondiente organización.
} 
funcionamiento. Así debe entenderse que sucede también en el caso del Municipio, la Provincia y la Isla, pues los artículos 140 y 141 CE se centran exclusivamente, en lo que ahora importa, en el carácter democrático de la organización, estableciendo el régimen de concejo abierto o de Ayuntamiento (con determinación del tipo de elección para los integrantes de éste: Alcalde y Concejales) para el primero, el carácter representativo de las Diputaciones u otras Corporaciones para la segunda y simplemente la $<<$ administración propia > para la tercera. Y así resulta también del $<<$ modelo europeo $>>$ de Administración Local plasmado en la Carta Europea de Autonomía Local ${ }^{30}$ : el artículo 3.2 de ésta es, en efecto, claro al disponer que el derecho al autogobierno local se ejerce mediante Asambleas o Consejos integrados por miembros elegidos y que pueden disponer de órganos ejecutivos responsables ante ellos mismos ${ }^{31}$. La perspectiva propia de la posición de los miembros de la colectividad organizada en entidad local, definida constitucionalmente en términos del derecho fundamental reconocido en el artículo 23.1 CE, en modo alguno contradice los argumentos anteriores, toda vez que el aludido derecho lo es exclusivamente a participar - directamente o a través de representantes- en los asuntos públicos, sin que el alcance de la participación derive directamente del contenido así constitucionalmente declarado; alcance que sólo puede resultar de los términos mismos de la configuración de las organizaciones públicas gestoras de los asuntos públicos de los que se predica la participación ciudadana. Todo lo cual vale especialmente para las organizaciones de la instancia territorial insular, teniendo en cuenta que por lo que hace a la Isla i) el artículo $141.4 \mathrm{CE}$ únicamente prescribe la existencia de una <<administración propia >> (sin especificar, como sí se hace para la Provincia, no digamos ya para el Municipio, el carácter necesariamente representativo de dicha administración), y ii) la interiorización relativa que resulta legítimamente del Estatuto de Autonomía (desde luego en el caso de las Islas Baleares y como ha quedado ya razonado) impone el reconocimiento a favor del legislador balear de un cierto margen $<<$ añadido $>>$ de configuración para adecuar la organización insular a las peculiaridades de la arquitectura autonómica del poder público administrativo.

Resulta, pues, que la clave del tipo <<autoadministración democrática > está en la construcción misma de la correspondiente organización (sobre la base del modelo corporativo) y de la estructura y funcionamien-

\footnotetext{
${ }^{30}$ Así lo he puesto de relieve ya en otra ocasión. Véase L. PAREjo Alfonso, «La regulación de los Consejos Insulares a la luz del marco constitucional y estatutario», op. cit. en nota n. ${ }^{\circ} 5$, p. 52.

${ }^{31}$ Órganos éstos para los que, por conclusión lógica evidente, ya no se exige que estén integrados por miembros elegidos.
} 
to democráticos de ésta, en términos que modulan las exigencias inherentes de suyo al principio democrático. La modulación procede de la nota $<<$ autoadministración $>>$, requirente de una específica imputación de la gestión de los intereses de la colectividad a los destinatarios de la misma. Esta específica imputación sólo es posible cuando el conjunto de la actividad gestora de la organización correspondiente está efectivamente en manos de órganos elegidos, es decir, integrados por personas con la cualidad de representantes en cuanto que elegidos por los miembros de la colectividad de que se trate ${ }^{32}$.

Siendo claro que el problema analizado no radica en el cumplimiento mismo del principio democrático, cuanto en la expresada modulación que éste experimenta por mor de la <<autoadministración>>, el análisis ha de centrarse en el requerimiento de imputación que ésta, como acaba de señalarse, comporta.

La instancia y el ordenamiento locales tienen, como he justificado en otro lugar ${ }^{33}$, una economía y lógica propias, diferenciadas desde luego de las de las instancias-ordenamientos territoriales superiores del Estado, de modo que no resulta lícito el simple traslado, la mera proyección a la Administración Local de los esquemas propios de la estructura y el funcionamiento de éstos. Desde esta perspectiva puede afirmarse que la <<autoadministración>> impone desde luego que todos los órganos dotados de legitimación democrática propia intervengan activamente en la gestión, es decir, sean decisorios y no simplemente deliberantes o fiscalizadores de la acción de otros órganos. La especificidad en la instancia local de la división funcional del poder, pues esta última se reproduce igualmente en aquélla, consiste justamente en que no puede discurrir netamente por la línea divisoria que marca la diferenciación, en el ciclo de la gestión pública, de la normación y la ejecución en sentido estricto. Así lo impone el carácter constitucional de la entera instancia local (en cualquiera de sus escalones: municipal y provincial o insular) como Administración pública. Los órganos superiores representativos han de ser decisorios en el entero campo de la gestión de los intereses colectivos correspondientes. De esta conclusión empero nada concreto se sigue sobre la economía y lógica peculiares de la división funcional en el seno de la instancia local, es decir, sobre el reparto de facultades decisorias entre los

\footnotetext{
${ }^{32}$ Lo que en modo alguno significa, como es obvio, que la totalidad de las decisiones, acciones y omisiones sean precisamente de estos órganos.

${ }^{33}$ Véase L. Parejo Alfonso, «Estado autonómico y Régimen local», Administración de Andalucía. Revista Andaluza de Administración Pública, número 42 (2001), p. 11 y ss.
} 
referidos órganos superiores representativos y ni siquiera de la naturaleza y entidad de las facultades decisorias que deban quedar retenidas. Pues la naturaleza de $<<$ configuración legal $>>$ de la autonomía local proporciona al respecto un amplio margen de opciones al legislador ordinario.

A este propósito debe recordarse ${ }^{34}$ que estando inscrita la autonomía local, toda ella y por la razón expuesta, en la $<<$ función ejecutiva $>>$ diseñada constitucionalmente, la gestión que le está también constitucionalmente atribuida se traduce igualmente en una actividad compleja, la acotada asimismo por la norma constitucional con la expresión $<<$ gobierno y administración $>>{ }^{35}$. Lo que quiere decir que la función constitucional desempeñada por la autonomía local presenta la doble dimensión derivada de la distinción entre actividad directiva (reservada en las instancias superiores a la organización conceptuada como $<<$ Gobierno $>>$ ) y actividad dirigida (típica y única, aunque no exclusiva, en las instancias superiores de la organización conceptuada como $<<$ Administración $>>$ ). La continuidad de esta distinción a lo largo de toda la organización territorial del Estado, alcanzando la instancia basal del mismo, se explica satisfactoriamente en la ya apuntada especificidad de la autonomía local ${ }^{36}$. La combinación de la autonomía y de la autoadministración democrática inscribe de suyo en la gestión local, en efecto, la posibilidad de la opción entre alternativas, es decir, la sustancia política, por más que el margen de aquéllas sea más estrecho que en las instancias territoriales superiores, más estrecho por acotado no solo por la Constitución o el bloque de la constitucionalidad, sino también por el entero bloque de la legalidad establecido justamente, en desarrollo de sus funciones constitucionales propias, por las dos instancias territoriales superiores. O dicho de otra forma: la acción de gobierno sólo pueda expresarse legítimamente en los términos de la discrecionalidad administrativa, normativa o de caso concreto ${ }^{37}$.

\footnotetext{
${ }^{34}$ Sobre ello, en detalle, L. Parejo Alfonso, Cuatro estudios..., op cit., en nota n. ${ }^{\circ} 5$, pp. 12 y sgs.; y también, con carácter general, en «Gobierno y Administración pública en la Constitución española», op cit. en nota n. ${ }^{\circ} 24$, p. 89 y ss.

${ }^{35}$ Las expresiones empleadas por los artículos 140 y 141.1 CE para los Municipios y las Provincias, respectivamente, son al respecto bien significativas, careciendo en este contexto de toda trascendencia el hecho de que el artículo 141.4 CE se refiere únicamente, para las Islas, a la <<administración propia >.

${ }^{36}$ La LbCI01 califica significativa y correctamente los órganos superiores representativos de los Consejos Insulares como <<órganos de gobierno >> (art. 7).

${ }^{37}$ Esta conceptuación del alcance del autogobierno local en nada se opone a la peculiaridad de la normación local (productora de normas estatutarias más que reglamentarias en sentido estricto). La especificidad de la discrecionalidad local en la normación deriva de las características del órgano de la que emana y remite a la necesaria reconstrucción de la institución de la reserva de ley cuando está en juego la autonomía local como principio de la distribución territorial del poder.
} 
El binomio actividad directiva-actividad dirigida y la consecuente dialéctica entre ambas son necesarios, por demás, para explicar satisfactoriamente la aludida sustancia política en el seno de una organización-función que es exclusivamente Administración. Pues permite combinar satisfactoriamente el predominio en ella del principio democrático (con el valor del pluralismo político) y de la técnica de la autoadministración como factores distintivos de legitimación con los generales de toda Administración que deben también otorgarle soporte: los de objetividad, servicialidad y eficacia con sumisión plena a la ley y al Derecho. Esa combinación satisfactoria se produce justamente cuando se reserva en todo caso el contenido funcional directivo a los órganos representativos y se complementa tal reserva con la asignación de las decisiones directivas esenciales o más importantes (desde el punto de vista del orden constitucional), incluyendo en ellas las de carácter normativo, al máximo órgano representativo colegiado-deliberante, de suerte que al órgano o los órganos propiamente ejecutivos solo restan las decisiones directivas bien de propuesta o impulso, bien menores o subordinadas o acantonadas en todo caso en el ámbito interno o de los servicios administrativos. De donde se sigue que la lógica de la instancia-ordenamiento local impone que la división funcional del poder de decisión en su seno responda a la expuesta combinación, que es capaz de producir una imagen característica capaz de servir de criterio para valorar su desnaturalización.

Aun siendo claro que toda la gestión estrictamente ejecutiva, incluida la derivada de las decisiones del máximo órgano representativo colegiadodeliberante, es responsabilidad del órgano o los órganos superiores representativos que tengan encomendada aquélla, la distinción que se viene manejando es igualmente operativa en el seno de dicha gestión. Pues en ella se hacen presentes con especial intensidad los factores de legitimación constitucional propios de la organización y la actividad administrativas igualmente en sentido estricto; especial intensidad, que hace retroceder en trascendencia - a medida que las decisiones están más densamente predeterminadas - el mecanismo de representación política. El equilibrio se alcanza aquí en la combinación de los factores de la que resulte la posibilidad en todo caso de imputación suficiente de las decisiones a los órganos superiores representativos ${ }^{38}$. Lo que vale decir aquélla en la que éstos retie-

\footnotetext{
${ }^{38}$ Imputación suficiente quiere decir aquí reconducción razonable de la entera actividad ejecutiva en sentido estricto a la colectividad institucionalizada por la correspondiente colectividad local a través de la responsabilidad política de los órganos superiores estrictamente ejecutivos ante el máximo órgano representativo colegiado-deliberante, gracias a la dirección plena y efectiva de aquélla (mediante el correspondiente y suficiente elenco de facultades decisorias) por la organización superior representativa que tenga asignada la responsabilidad sobre dicha actividad.
} 
nen todas las facultades precisas no ya solo para dirigir ex ante la acción de la entera organización administrativa, sino para controlar ésta incluso caso a caso, es decir, por relación a decisiones concretas. Pues de la opción constitucional por el tipo de autoadministración democrática no puede hacerse derivar la exigencia de toma de todas las decisiones directamente por los órganos representativos, en tanto que contradictoria ésta con el paralelo diseño general de la Administración y de sus exigencias propias de objetividad y eficacia con sometimiento pleno a la ley y al Derecho. Esta contradicción se da desde luego en los supuestos de colectividades locales amplias y complejas. De ahí que desde siempre el régimen local, incluso el actual ${ }^{39}$, haya admitido y admita la modulación de la organización y el funcionamiento de las entidades municipales de mayor entidad precisamente en el sentido de admitir la introducción de órganos de gestión ejecutiva de libre designación y remoción (sin legitimación democrática propia, por tanto, aunque dirigidos por los que si la tienen). Y de ahí también que en la actualidad se esté considerando la procedencia de extender dicha modulación, como ya se ha tenido ocasión de exponer al principio de este trabajo, a todas las $<<$ grandes ciudades $>>$. No otra solución es, en efecto, posible cubriendo como cubre el tipo de autoadministración democrática un abanico muy abierto de colectividades, desde las rurales con contados vecinos hasta las aglomeraciones urbanas de millones de ellos. Así lo acredita ya el dato relevante de la predeterminación constitucional (art. $140 \mathrm{CE}$ ) de la organización municipal sobre dos fórmulas dirigidas a cubrir los dos supuestos principales en que cabe encuadrar el heterogéneo mundo local: el Concejo abierto (la autoadministración directa) para las colectividades pequeñas y simples y el Ayuntamiento elegido (la autoadministración a través de representantes). Y si esto es así incluso para el Municipio, el escalón de la Administración local constitutivo del modelo mismo del diseño constitucional de ésta, con mayor razón lo es en el escalón provincial-insular de la misma, tanto más cuando éste es objeto del grado de interiorización autonómica ya razonado para los Consejos insulares.

El tipo constitucional de administración que representa la Administración local admite, pues y cuando de los supuestos de procedencia de la autoadministración a través de representantes se trata, configuraciones diversas en el plano de la legislación ordinaria. El núcleo último definitorio del tipo y constitutivo del límite del margen de configuración legal (traspasado el cual se incurre en inconstitucionalidad por desfiguración del tipo) puede identificarse con las siguientes notas:

${ }^{39}$ Como resulta de la disposición adicional sexta, relativa a los regímenes especiales de Madrid y Barcelona, de la vigente Ley 7/1985, de 2 de abril, reguladora de las bases del régimen local. 
- La reserva a los órganos superiores representativos de la función directiva.

- La preservación de la división funcional interna mediante la atribución del contenido decisional esencial o más importante al máximo órgano representativo colegiado-deliberante, con reducción de la organización representativa restante al campo de la ejecución en sentido estricto.

- La reserva a los órganos superiores representativos encargados de la ejecución en sentido estricto de las facultades decisorias precisas para asegurar su dirección plena y efectiva (con carácter previo o en sede de control) de la total organización administrativa responsable de la referida ejecución.

Incluso sin tener en cuenta la legitimación reforzada que para el establecimiento de su contenido dispositivo supone desde luego el bloque de la constitucionalidad en el que se inscribe, la LbCI01 respeta desde luego el núcleo así identificado.

Por de pronto en la Ley:

a) El $<<$ gobierno $>>$ (es decir, la entera función directiva) se encomienda en exclusiva a los órganos superiores representativos, unipersonales y colegiados: artículo 7 .

b) La decisión en los asuntos esenciales o más importantes (y desde luego las normas, incluso cuando deban revestir la forma de planes) se reserva al Pleno: art. 8, quedando acantonados los restantes órganos superiores representativos en el contenido funcional del <<gobierno y administración $>>$ correspondiente al impulso y la iniciativa de la acción corporativa y la gestión estrictamente ejecutiva [como resulta del art. 9.1 y 2, a)].

Dicho esto, no parece que pueda ponerse seriamente en duda que los órganos representativos propiamente ejecutivos mantienen la dirección y el control de la entera actividad administrativa en la opción organizativa de no previsión del Consejo Ejecutivo que concede el legislador, ni siquiera en la hipótesis del régimen especial contemplado en el artículo 14 LbCI01. Pues las direcciones insulares y las secretarías técnicas a que este precepto se refiere son ciertamente órganos unipersonales directivos, dotados incluso de facultades decisorias, pero son de libre decisión y remoción por la Presidencia del Consejo y actúan siempre bajo la dirección y autoridad del correspondiente Consejero insular, el cual es también siempre un miembro de la Comisión de Gobierno, es decir, un órgano colegiado repre- 
sentativo (integrado exclusivamente por miembros que, si designados por la Presidencia, tienen necesariamente la condición de representantes elegidos). Y todos los Consejeros operan bajo la superior dirección y la coordinación de la Presidencia, siendo la acción de ésta y la de la Comisión de Gobierno plenamente fiscalizables por el Pleno del Consejo Insular.

Pero tampoco parece que pueda cuestionarse con fundamento, en cuanto a idéntico extremo, la opción organizativa, también permitida por el legislador, que incluye el Consejo Ejecutivo y determina la transformación de la Comisión de Gobierno en un órgano representativo que refleja la composición política del Pleno. Pues en este caso todos los miembros del Consejo Ejecutivo, que ciertamente dirigen los correspondientes departamentos ${ }^{40}$ son de libre designación y remoción por la Presidencia y actúan bajo la dirección y coordinación de la Presidencia, respondiendo de su gestión no solo ante ésta, sino también — cuando así lo requiera- del Pleno (art. 13. LbCI01). Y los acuerdos del Consejo Ejecutivo como tal son recurribles en alzada ante la Comisión de Gobierno reproductora de la composición política del Pleno [art. 10.2, a), en relación con el art. 7.3, párr. 2. ${ }^{\circ}$ LbCI01].

\footnotetext{
${ }^{40}$ Articulados internamente en órganos igualmente directivos — direcciones insulares y secretarías técnicas- pero también de libre designación y remoción por la Presidencia y actuantes bajo la dirección inmediata del correspondiente Consejero y, por tanto, la superior última de la Presidencia (art. 13 LbCI01).
} 